\title{
Transient Formation and Reactivity of a High-Valent Nickel(IV) Oxido Complex
}

Sandeep K. Padamati, ${ }^{\dagger}$ Davide Angelone, ${ }^{\dagger}{ }^{\dagger}$ Apparao Draksharapu, ${ }^{\dagger}$ Gloria Primi, ${ }^{\dagger}$ David J. Martin, ${ }^{\S(0)}$

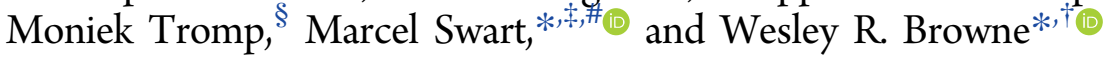

${ }^{\dagger}$ Molecular Inorganic Chemistry, Stratingh Institute for Chemistry, Faculty of Science and Engineering, University of Groningen, Nijenborgh 4, 9747AG, Groningen, The Netherlands

${ }^{\ddagger}$ IQCC \& Departament de Química, Universitat de Girona, Campus Montilivi (Ciències), 17003 Girona, Spain

"ICREA, Pg. Lluís Companys 23, 08010 Barcelona, Spain

${ }^{\S}$ Sustainable Materials Characterisation, Van’t Hoff Institute for Molecular Sciences, University of Amsterdam, Science Park 904, 1098 XH Amsterdam, The Netherlands

Supporting Information

ABSTRACT: A reactive high-valent dinuclear nickel(IV) oxido bridged complex is reported that can be formed at room temperature by reaction of $\left[(\mathrm{L})_{2} \mathrm{Ni}(\mathrm{II})_{2}(\mu-\mathrm{X})_{3}\right] \mathrm{X}(\mathrm{X}=\mathrm{Cl}$ or $\mathrm{Br})$ with $\mathrm{NaOCl}$ in methanol or acetonitrile (where $\mathrm{L}=1,4,7-$ trimethyl-1,4,7-triazacyclononane). The unusual $\mathrm{Ni}(\mathrm{IV})$ oxido species is stabilized within a dinuclear tris- $\mu$-oxido-bridged structure as $\left[(\mathrm{L})_{2} \mathrm{Ni}(\mathrm{IV})_{2}(\mu-\mathrm{O})_{3}\right]^{2+}$. Its structure and its reactivity with organic substrates are demonstrated through a combination of UV-vis absorption, resonance Raman, ${ }^{1} \mathrm{H}$ NMR, EPR, and Xray absorption (near-edge) spectroscopy, ESI mass spectrometry, and DFT methods. The identification of a Ni(IV)-O species opens opportunities to control the reactivity of $\mathrm{NaOCl}$ for selective oxidations.

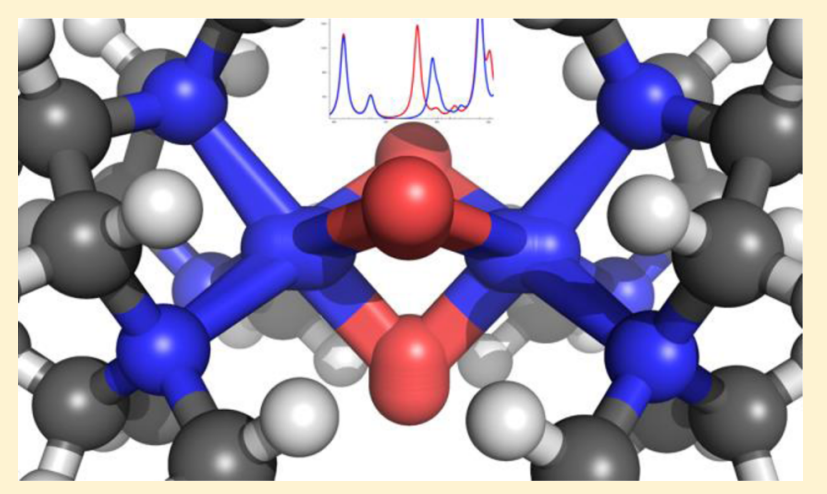

\section{INTRODUCTION}

Metalloenzymes are central to the functioning of biological systems, especially in oxidative transformations and protection against reactive oxygen species. ${ }^{1} \mathrm{Fe}-, \mathrm{Cu}-$, and $\mathrm{Mn}$-dependent metalloenzymes have been studied extensively and have stimulated the design and synthesis of structural and functional model complexes, especially in the search for synthetic analogues of reactive bioinorganic intermediates. ${ }^{2}$ Recently, attention has turned to synthetic nickel-based complexes due to both enzymes such as NOD (nickel oxide dismutase) ${ }^{3}$ and their potential in the activation of small molecules, including $\mathrm{H}_{2} \mathrm{O}_{2}{ }^{4}$ mCPBA, ${ }^{5}$ and $\mathrm{NaOCl}^{6}$ In the latter case, such complexes open the possibility to achieve selective alkane chlorination and alkane and alkene oxygenation.

Recently, several high-valent $\left(\mathrm{Ni}(\mathrm{III})^{4,7}\right.$ and $\mathrm{Ni}(\mathrm{IV})^{6 c, 8}$ ) intermediates were identified spectroscopically. In contrast to organometallic $\mathrm{Ni}(\mathrm{IV})$ complexes, ${ }^{8}$ the formation of $\mathrm{Ni}(\mathrm{III})$ and, more so, $\mathrm{Ni}(\mathrm{IV})$ oxido complexes, although inferred, is controversial due to the implications of the oxo-wall premise. Nevertheless, several $\mathrm{Ni}(\mathrm{II})$ and $\mathrm{Ni}(\mathrm{III})$ oxido or peroxido complexes, formed with $\mathrm{O}_{2}$ and $\mathrm{H}_{2} \mathrm{O}_{2}$, have been characterized already at low temperature. ${ }^{24-27}$

Here we show that a novel room-temperature-stable dinuclear $\mathrm{Ni}(\mathrm{IV})$ oxido complex (3), $\left[(\mathrm{L})_{2} \mathrm{Ni}(\mathrm{IV})_{2}(\mu-\mathrm{O})_{3}\right]^{2+}$ (where $\mathrm{L}=1,4,7$-trimethyl-1,4,7-triazacyclononane), can be generated by reaction of the $\mathrm{Ni}$ (II) complexes $(\mathbf{1}, 2)$ with $\mathrm{NaOCl}$ (Scheme 1). The high oxidation state of $\mathbf{3}$ is stabilized

Scheme 1. Formation of 3 from 1 and $\mathrm{NaOCl}$

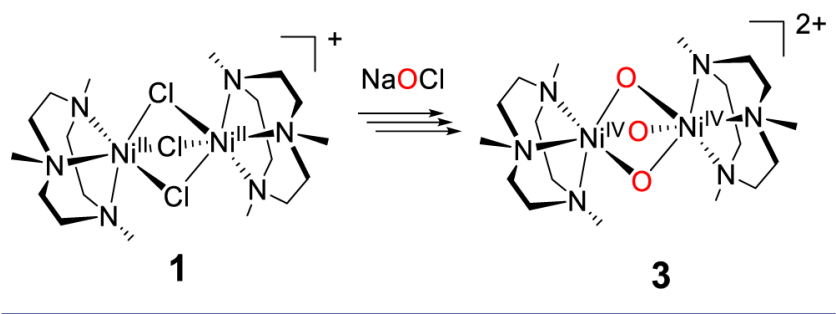

by the tris- $\mu$-oxido-bridged dinuclear structure. Furthermore, the reactivity of 3 toward direct $\mathrm{C}-\mathrm{H}$ oxidation of organic substrates is demonstrated.

Complex 3 is obtained within seconds of addition of near stoichiometric amounts of $\mathrm{NaOCl}$ to $\left[(\mathrm{L})_{2} \mathrm{Ni}(\mathrm{II})_{2}(\mu-\mathrm{X})_{3}\right] \mathrm{X}$. $\left(\mathrm{H}_{2} \mathrm{O}\right)_{n}(\text { where } \mathrm{X}=\mathrm{Cl}(\mathbf{1}) \text { or } \mathrm{Br}(2), n=5 \text { or } 7)^{10}$ in methanol or acetonitrile at room temperature. The structure of 3 was elucidated through a combination of UV-vis absorption and resonance Raman spectroscopy and ESI mass spectrometry,

Received: April 24, 2017

Published: June 5, 2017 
supported by isotope labeling, crossover experiments, and DFT methods.

\section{RESULTS AND DISCUSSION}

Complexes 1 and $\mathbf{2}$ were prepared by methods analogous to those reported earlier (see SI for details). ${ }^{10}$ The Raman spectra of $\mathbf{1}$ in the solid state (Figure S1) and in solution (i.e., methanol, acetonitrile, Figure S2) indicate that the complexes retain their structure; that is, the ligand $(\mathrm{L})$ remains bound to $\mathrm{Ni}$ (II) upon dissolution. However, ESI mass spectrometry indicates that $\mathbf{1}$ can form mononuclear complexes with three $\left.\left(176.3 \mathrm{~m} / z: 4\left[(\mathrm{~L}) \mathrm{Ni}(\mathrm{II})\left(\mathrm{CH}_{3} \mathrm{CN}\right)_{3}\right)\right]^{2+}\right)$ or two acetonitrile ligands $\left(155.9 \mathrm{~m} / z: 5,\left(\left[(\mathrm{~L}) \mathrm{Ni}(\mathrm{II})\left(\mathrm{CH}_{3} \mathrm{CN}\right)_{2}\right)\right]^{2+}\right)$ by substitution of the chlorido ligands (Figure S3). Indeed, mixtures of 1 and 2 show rapid exchange of $\mathrm{Cl}^{-}$and $\mathrm{Br}^{-}$ligands (Figure S4). The ${ }^{1} \mathrm{H}$ NMR spectrum of $\mathbf{1}$ in acetonitrile shows paramagnetically shifted and broadened signals at ca. 60, 90, and $120 \mathrm{ppm}$ (Figure S5), and its UV-vis absorption spectrum in methanol and acetonitrile (Figure S6) shows bands at 384, 635, and $1014 \mathrm{~nm}$. The DFT data (vide infra) indicate antiferromagnetically coupled $\mathrm{Ni}$ (II) ions in $\mathbf{1}$ and $\mathbf{2}$, consistent with observations by Wieghardt et al. ${ }^{11}$ The $C_{3 h}$-symmetric DFT structure for both $\mathbf{1}$ and $\mathbf{2}$ is in excellent agreement with the X-ray structure, ${ }^{11}$ with differences of ca. 0.01-0.02 $\AA$ between DFT and $\mathrm{X}$-ray for $\mathrm{Ni}-\mathrm{N}, \mathrm{Ni}-\mathrm{Cl} / \mathrm{Br}$, and $\mathrm{Ni}-\mathrm{Ni}$ distances (Table S1). The antiferromagnetically coupled state lies lowest in energy (including COSMO solvation ${ }^{12}$ and ZORA $^{13}$ relativistic effects, Table S2), ${ }^{14,15}$ in excellent agreement with experiment. ${ }^{11}$ In this state, the locally spin-polarized triplet $(S=1) \mathrm{Ni}$ (II) ions couple antiferromagnetically (AFM) to reach overall an open-shell singlet state. As a result, spin-up spin-density is observed around one $\mathrm{Ni}$ and spin-down around the other (Figure 1). This AFM state is only $0.3 \mathrm{kcal} \cdot \mathrm{mol}^{-1}$

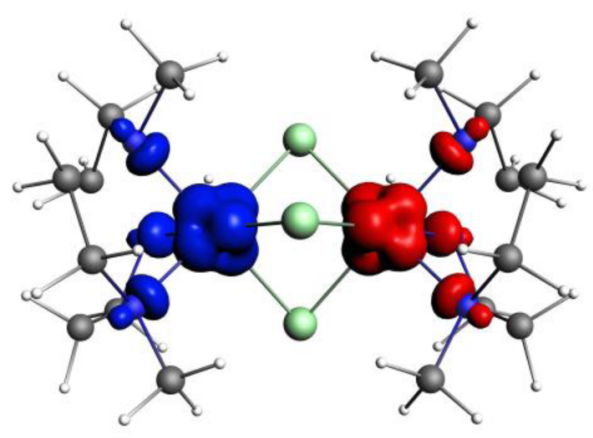

Figure 1. Spin-density plot (S12g/TZ2P) for (antiferromagnetically coupled) 1 with spin-up spin-density shown in blue (around $\mathrm{Ni}_{3}$ left) and spin-down spin-density in red (around $\mathrm{Ni}_{\mathrm{b}}$, right).

lower than the ferromagnetically (FM) coupled $(S=2)$ state (see SI section 7 for the corresponding spin-density plot). Both states would be consistent with the paramagnetic ${ }^{1} \mathrm{H}$ NMR shifts (vide supra), but the AFM state is found to be slightly lower by both theory and experiment. The diamagnetic closedshell singlet state, in which the $\mathrm{Ni}$ (II) ions are now locally in a closed-shell $(S=0)$ state, is higher in energy than the AFM state by $37.7 \mathrm{kcal} \cdot \mathrm{mol}^{-1}(\mathbf{1})$ and $35.0 \mathrm{kcal} \cdot \mathrm{mol}^{-1}(2)$. Finally, also an overall intermediate spin state $(S=1)$ was obtained, $25.5 \mathrm{kcal} \cdot \mathrm{mol}^{-1}$ (1) and $23.4 \mathrm{kcal} \cdot \mathrm{mol}^{-1}$ (2) higher in energy than the AFM state, where spin-density corresponding to the single occupation of an antibonding $\mathrm{d}_{x^{2}-y^{2}}$ orbital was observed on both Ni ions. Finally, the experimental NMR and UV-vis absorption spectra of the AFM state are similar to those of related $\mathrm{Ni}(\mathrm{II})$ complexes (Figure S7). ${ }^{16}$

Addition of $\mathrm{NaOCl}$ to $\mathbf{1}$ or $\mathbf{2}$ in methanol or in acetonitrile leads to a rapid increase in absorbance at 363 and $612 \mathrm{~nm}$ due to formation of 3 (Figure 1). In methanol, the visible absorption band decreases with a $t_{1 / 2}$ of ca. $50 \mathrm{~s}$ at $20{ }^{\circ} \mathrm{C}$ (Figure S8), and the absorption spectrum after $20 \mathrm{~min}$ is similar to the initial spectrum, with only a minor shift from 388 to 378 $\mathrm{nm}$ (Figure 2). Notably, the rate of decay of 3 in methanol was

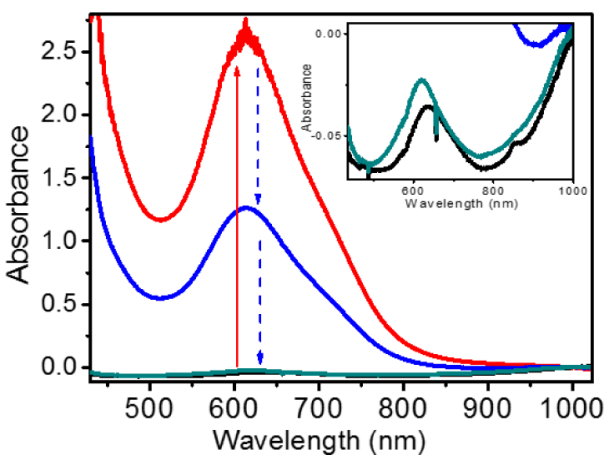

Figure 2. UV-vis absorption spectrum of 1 (3.5 mM) in methanol before (black) and after (red $6 \mathrm{~s}$, blue $48 \mathrm{~s}$, green $463 \mathrm{~s}$ ) addition of 11 equiv of $\mathrm{NaOCl}(\mathrm{aq})$ at $293 \mathrm{~K}$. Inset: Expansion of the NIR region. The data indicate that for $3 \varepsilon_{612 \mathrm{~nm}}>715 \mathrm{M}^{-1} \cdot \mathrm{cm}^{-1}$.

substantially lower than the rate of the direct reaction of $\mathrm{NaOCl}$ with methanol in the absence of 1 (Figure S8), indicating that the formation of 3 competes with oxidation of methanol by $\mathrm{NaOCl}$ and that 3 is less reactive in the oxidation of methanol than $\mathrm{NaOCl}$.

In both the presence and absence of $\mathbf{1}$, near-quantitative (cf. $\mathrm{NaOCl}$ ) oxidation of methanol to formaldehyde occurs (1.5:1, Figure S9), indicating that although at least 2 equiv of $\mathrm{NaOCl}$ are consumed in forming 3 from $\mathbf{1}$, these oxidation equivalents are still available for subsequent oxidation of methanol. Further additions of $\mathrm{NaOCl}$ in the presence of $\mathbf{1}$ resulted in the reappearance of the $612 \mathrm{~nm}$ absorption (Figure S10), confirming the integrity of the catalyst under reaction conditions. Similar changes were observed with $\mathrm{NaOBr}$ (Figure $\mathrm{S} 11$ ), which indicates that the same intermediate is formed with both oxidants (vide infra). Addition of $\mathrm{H}_{2} \mathrm{O}_{2}$ or purging with $\mathrm{O}_{2}$ (Figures S12 and S13) did not result in the appearance of 3.

Intermediate 3 forms upon addition of $\mathrm{NaOCl}$ to 1 also in acetonitrile (absorbance band at $612 \mathrm{~nm}$ ), but persists for a substantially longer time period than in methanol, with a $t_{1 / 2}$ of ca. $10 \mathrm{~min}$ at $20^{\circ} \mathrm{C}$ and over $6 \mathrm{~h}$ at $-15{ }^{\circ} \mathrm{C}$ (Figures S14 and $\mathrm{S} 15$ ), enabling characterization by resonance Raman spectroscopy, XANES, XES, and ESI mass spectrometry and reactivity with other substrates to be studied (vide infra). The maximum transient absorbance at $612 \mathrm{~nm}$ was obtained with 3-4 equiv of $\mathrm{NaOCl}$ (Figure S16) and is accompanied by an increase in oxidation state as confirmed by XANES and XES (Figure 3 and Figure S17).

The $\mathrm{Ni} \mathrm{K}$ edge $\mathrm{X}$-ray absorption near edge structure (XANES) as well as the X-ray emission (XES) spectra were recorded for $1(30 \mathrm{mM})$ in acetonitrile before and after addition of $\mathrm{NaOCl}$. Spectra were acquired over $5 \mathrm{~min}$ after addition when the concentration of 3 (generated from 1) was substantial, although $\mathrm{Ni}$ (II) species are present also. The Ni K edge XANES spectra of both $\mathbf{1}$ and the mixture of species formed after addition of $\mathrm{NaOCl}$ show a nondescript edge, i.e., 

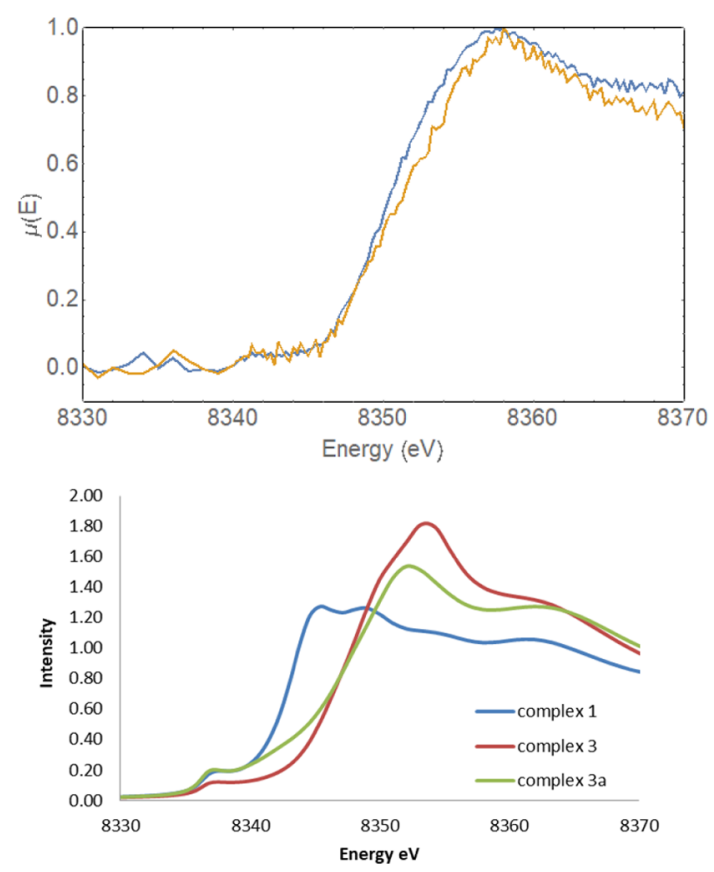

Figure 3. (Top) Ni K XANES before (blue) and after (yellow) addition of 4 equiv of $\mathrm{NaOCl}$ to $1(30 \mathrm{mM})$ in acetonitrile. (Bottom) $\mathrm{Ni} \mathrm{K}$ edge XANES for structures 1, 3, and 3a, simulated using FEFF9. $0^{18}$ using coordinates available from DFT-optimized structures (see the SI).

no significant pre- edge features, which indicates a nearoctahedral, six-coordinated, geometry around the Ni center for all species present (consistent with the structures 1, 3, and 3a).

The edge position is a function of the ligands present and geometry as well as oxidation state, and hence a direct conclusion based on XANES alone cannot be drawn. For example, for purely oxidic Ni systems, an energy shift of about $1.8 \mathrm{eV}$ per oxidation state is reported, with a much lower shift for sulfur-based systems. ${ }^{17}$ A conclusive statement as to the oxidation state requires the availability of a series of reference compounds with similar ligands and geometries (data for closely related structures are not yet available in the literature).

The energy shift of about $2 \mathrm{eV}$ observed in the experimental spectra is consistent with an increase in oxidation state, but it will also reflect the change from chlorido to oxido ligands. Furthermore, the mixture of species available (including Ni(II)) reduces the magnitude of the observed shift and complicates interpretation.

The simulated XANES for complexes 1, 3, and 3a are displayed in Figure $3 .^{18}$ All XANES spectra have only a preedge feature at low energy and an otherwise featureless edge, consistent with six-coordinated geometries. A clear difference in the spectra of the $\mathrm{Ni}(\mathrm{II}) \mathbf{1}$ of $5 \mathrm{eV}$ with the $\mathrm{Ni}$ (III) $3 \mathrm{a}$ and $\mathrm{Ni}$ (IV) 3a species is calculated, i.e., upon oxidation and change of ligands from $\mathrm{Cl}$ to $\mathrm{O}$. It is, however, also clear that XANES data will not allow for distinguishing the $\mathrm{Ni}(\mathrm{III})$ and $\mathrm{Ni}(\mathrm{IV})$ species, i.e., complexes 3 and 3 a. Furthermore, the Ni K edge XANES of 1 undergoes only a few electronvolts shift in the presence of $\mathrm{NaOCl}$ and not the full $5 \mathrm{eV}$ shift, as it is a mixture of $\mathrm{Ni}$ (II) and nickel in higher oxidation states, resulting in only an average shift, i.e., between 2 and $3 \mathrm{eV}$, reflecting an overall average increase in oxidation state. The XES data at the $\mathrm{K}_{\beta 1,3}$ edge also display an overall shift of a few electronvolts; however, the emission lines are sensitive to both oxidation state and ligand type also.

The three broad signals in the ${ }^{1} \mathrm{H}$ NMR spectrum of $\mathbf{1}$ in acetonitrile decrease upon addition of $\mathrm{NaOCl}$, suggesting the formation of a diamagnetic species, and then recover concomitant with the increase and decrease in absorbance at $612 \mathrm{~nm}$ (Figure S18). Samples flash frozen to $77 \mathrm{~K}$ at any time, however, did not indicate the presence of a mononuclear $\mathrm{Ni}(\mathrm{III})$ species by X-band EPR spectroscopy.

Generation of $\mathbf{3}$ by electrochemical oxidation of $\mathbf{1}$ was explored also. The cyclic voltammetry of 1 shows irreversible redox waves at 1.52, 1.35, and $1.05 \mathrm{~V}$ and an irreversible redox wave at $0.58 \mathrm{~V}$ on the return cycle. At higher scan rates (up to $10 \mathrm{~V} \mathrm{~s}^{-1}$ ) the initial oxidation wave at $1.05 \mathrm{~V}$ shows some evidence of chemical reversibility; however, the shifts in $I_{\mathrm{p}, \mathrm{a}}$ (which are corrected for $\mathrm{IR}_{\mathrm{u}}$ ) indicate that the oxidation is electrochemically irreversible also (Figure S19). Addition of $\mathrm{NaOCl}$ to 1 results (after $2 \mathrm{~min}$ ) in a shift in the oxidation wave to $1.16 \mathrm{~V}$, indicative of ligand exchange, e.g., $\mathrm{CH}_{3} \mathrm{CN}$ replacing $\mathrm{Cl}^{-}$. It should be noted, however, that the redox chemistry of $\mathrm{NaOCl}$, concentration polarization, and the likely complex series of dis- and comproportionation reactions between $\mathbf{1}$ and 3 preclude the observation of a redox wave assignable to 3 . One hour after addition of $\mathrm{NaOCl}$, a further shift is observed, indicating ligand exchange to form a $\mathrm{Ni}$ (II) complex similar to 4 (Figure S20). Notably the voltammetry and spectroelectrochemistry were not affected substantially by the addition of water and $\mathrm{NaCl}$ (i.e., at concentrations present under reaction conditions).

The spectroelectrochemistry of $\mathbf{1}$ in acetonitrile shows that oxidation at $1.2 \mathrm{~V}$ leads to essentially no change in the UV absorption (Figure S21a). On the second cycle the redox wave is shifted to $>1.58 \mathrm{~V}$; again relatively little change in absorbance is observed, and after reduction below $0.86 \mathrm{~V}$ only minor shifts in absorbance at ca. $300 \mathrm{~nm}$ are observed, consistent with ligand exchange (Figure S21b). Bulk electrolysis of 1 shows an increase in absorption at $344 \mathrm{~nm}$; however, the EPR spectrum (X-band $77 \mathrm{~K}$ ) of this sample was silent, and hence oxidation leads to ligand exchange to a $\mathrm{Ni}(\mathrm{II})$ complex with a more positive redox potential rather than formation of a $\mathrm{Ni}(\mathrm{III})$ or $\mathrm{Ni}(\mathrm{IV})$ complex.

Attempts to isolate 3 by flash precipitation with $\mathrm{KPF}_{6}$ yielded the mononuclear $\mathrm{Ni}(\mathrm{II})$ compound $\left[(\mathrm{L}) \mathrm{Ni}(\mathrm{II})\left(\mathrm{CH}_{3} \mathrm{CN}\right)_{3}\right]^{2+}$ (4) instead, reported earlier by Tak et al. as the $\mathrm{B}(\mathrm{Ph})_{4}{ }^{-}$salt, ${ }^{16}$ in which the chlorido ligands are replaced by acetonitrile ligands to form a mononuclear complex (see the SI and Scheme 2). Notably, addition of $\mathrm{NaOCl}$ to 4 in acetonitrile results in the same visible absorption spectrum as obtained with 1 (Figure S23), indicating that the formation of 3 is not dependent on the initial form of the $\mathrm{LNi}$ (II) complex (with $\left.\mathrm{Cl}^{-} / \mathrm{Br}^{-} / \mathrm{CH}_{3} \mathrm{CN}\right)$ and is consistent with the rapid equilibration of these species in solution. Furthermore, addition of $\mathrm{NaOCl}$ (4-10 equiv) to a $1: 1$ mixture of $\mathrm{NiCl}_{2}$ and the ligand (L) in acetonitrile results in the appearance of the bands at $\lambda_{\max }$ 363 and $612 \mathrm{~nm}$ (Figure S24), consistent with a maximum 50\% conversion to 3 . In the absence of ligand (i.e., only $\mathrm{NiCl}_{2}$. $6 \mathrm{H}_{2} \mathrm{O}$ ) the band at $612 \mathrm{~nm}$ was not observed (Figure S25).

In earlier reports, ${ }^{6}$ the presence of acetic acid was necessary for the formation of high-valent nickel complexes with $\mathrm{NaOCl}$. Addition of acetic acid (4.5 equiv) to 3 in acetonitrile (generated by addition of 4.5 equiv of $\mathrm{NaOCl}$ to 1 (0.9 $\mathrm{mM})$ ) did not affect the absorbance at $612 \mathrm{~nm}$ significantly (Figure S26a). In contrast, addition of acetic acid (4.5 equiv) 
Scheme 2. Formation of 3 from 1 and $\mathrm{NaOCl}$ and Subsequent Decay to 4 in Acetonitrile

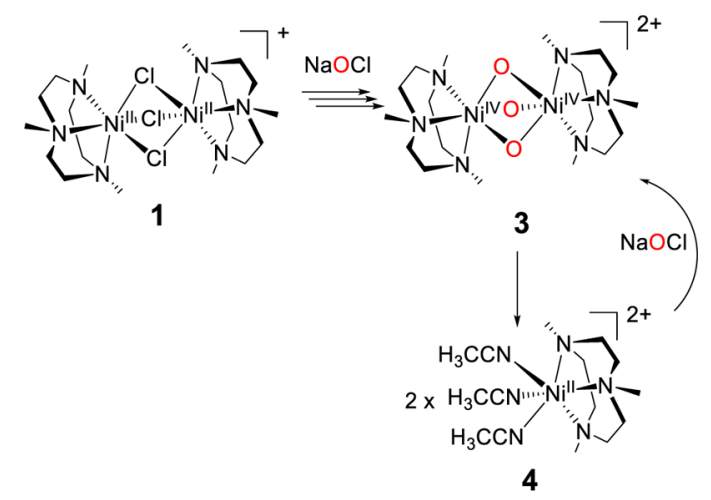

prior to addition of $\mathrm{NaOCl}$ to $\mathbf{1}(0.9 \mathrm{mM})$ precluded the appearance of the $612 \mathrm{~nm}$ band and hence formation of 3 (Figure S26b). ${ }^{19}$

The ESI mass spectra of $\mathbf{1}$ in acetonitrile show signals $(\mathrm{m} / z)$ assignable to $\left[\mathrm{Ni}(\mathrm{II})(\mathrm{L})\left(\mathrm{CH}_{3} \mathrm{CN}\right)_{2}\right]^{2+}(155.9 \mathrm{~m} / z),[\mathrm{Ni}(\mathrm{II})-$ (L) $\left.\left(\mathrm{CH}_{3} \mathrm{CN}\right)_{3}\right]^{2+}(176.3 \mathrm{~m} / z),[\mathrm{Ni}(\mathrm{II})(\mathrm{L})(\mathrm{Cl})]^{+}(264.1 \mathrm{~m} / z)$, and $\left[\mathrm{Ni}(\mathrm{II})_{2}(\mathrm{~L})_{2}(\mathrm{Cl})_{3}\right]^{+}(565.2 \mathrm{~m} / z)$ (Figure S27). The spectrum obtained from a solution containing 3 shows an additional strong signal at $253.3 \mathrm{~m} / z$ with an isotope distribution consistent with two $\mathrm{Ni}$ centers (Figure S28), regardless of whether it was generated with $\mathrm{NaOBr}$ or $\mathrm{NaOCl}$ and with $\mathbf{2}$ in place of $\mathbf{1}$ (Figures S29-S33). Notably, however, the signal increased by $3 \mathrm{~m} / z$ units with $\mathrm{Na}^{18} \mathrm{OCl}$ (Figure S31). The $\mathrm{m} / z$ signal at 253.3 is therefore consistent with structures such as the peroxy-bridged $3 \mathrm{a}^{20}\left[(\mathrm{~L})_{2} \mathrm{Ni}(\mathrm{III})_{2}(\mu-\mathrm{O})(\mu\right.$-O$\mathrm{O})]^{2+}$, the mono- $\mu$-oxo-bis-terminal-oxo $3 \mathrm{~b},[(\mathrm{~L})-(\mathrm{O})=\mathrm{Ni}$ $(\mathrm{IV})-\mathrm{O}-\mathrm{Ni}(\mathrm{IV})=(\mathrm{O})-\mathrm{L}]^{2+}$, and the tri- $\mu$-oxido-bridged 3 , $\left[\left((\mathrm{L})_{2} \mathrm{Ni}(\mathrm{IV})_{2}(\mu-\mathrm{O})_{3}\right]^{2+}\right.$ (Scheme 3$)$, with the latter structure 3 favored on the basis of Raman spectroscopy (vide infra) and DFT. $^{21}$

Scheme 3. Structures (3, 3a, 3b) Consistent with ESI Mass Spectral Data and Calculated Driving Forces for Their Formation from 1
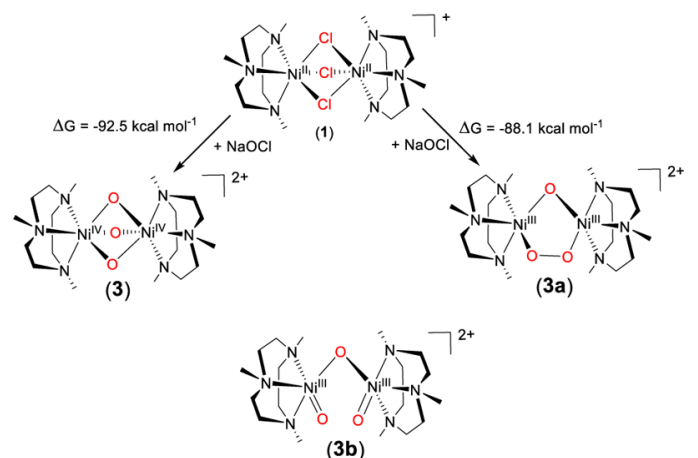

(3b)

All possible spin states were explored by DFT methods for 3, 3a, and $3 \mathbf{b}$. As expected for the $\mathrm{d}^{6} \mathrm{Ni}$ (IV) ions in 3, the lowest energy ${ }^{15}$ state corresponds to locally closed-shell singlet $(S=0)$ $\mathrm{Ni}(\mathrm{IV})$ ions. For consistency, we explored the possibility of other spin states and found several higher lying spin states, where, for example, the $\mathrm{Ni}(\mathrm{IV})$ ions had locally a triplet $(S=1)$ state that coupled to form overall a quintet $(S=2)$ state. However, these other spin states are $>27 \mathrm{kcal} \cdot \mathrm{mol}^{-1}$ higher in energy (see Table S2) and will not be discussed any further.
For the $d^{7} \mathrm{Ni}(\mathrm{III})$ ions in $3 \mathrm{a}$, the lowest energy ${ }^{15}$ state corresponds to a doublet on each of the metals, which can be FM $(S=1)$ or AFM (open-shell singlet) coupled. The latter open-shell singlet state is lower in (Gibbs free) energy than the triplet by $2.1 \mathrm{kcal} \cdot \mathrm{mol}^{-1}$, and $5.1 \mathrm{kcal} \cdot \mathrm{mol}^{-1}$ lower than the diamagnetic closed-shell singlet state. All other spin states for 3a are $>10 \mathrm{kcal} \cdot \mathrm{mol}^{-1}$ higher in (Gibbs free) energy. The lowest energy for the $d^{6} \mathrm{Ni}(\mathrm{IV})$ ions in $\mathbf{3 b}$ corresponds to an AFM state, where each of the $\mathrm{Ni}(\mathrm{IV})$ ions is found locally in a triplet $(S=1)$ state. The AFM state is lower than the FM state in $3 \mathrm{~b}$ by $1.2 \mathrm{kcal} \cdot \mathrm{mol}^{-1}$, with the other spin states higher in energy by $>10 \mathrm{kcal} \cdot \mathrm{mol}^{-1}$.

The geometrical parameters for compound 3, which although isostructural to $\left[(\mathrm{L})_{2} \mathrm{Mn}(\mathrm{IV})_{2}(\mu-\mathrm{O})_{3}\right]^{2+, 22}$ are found to be somewhat different. The most prominent feature in $\left[(\mathrm{L})_{2} \mathrm{Mn}\right.$ $\left.(\mathrm{IV})_{2}(\mu-\mathrm{O})_{3}\right]^{2+}$ is a short $\mathrm{Mn}(\mathrm{IV})-\mathrm{Mn}(\mathrm{IV})$ distance of $2.30 \AA$, which is absent in 3 , where the $\mathrm{Ni}(\mathrm{IV})-\mathrm{Ni}(\mathrm{IV})$ is instead 2.46 $\AA$; the latter distance is more similar to the bis- $\mu$-oxo variant $\left[\mathrm{L}_{2} \mathrm{Mn}_{2}{ }_{2}(\mathrm{O})_{2}(\mu-\mathrm{O})_{2}\right](2.62 \AA) .{ }^{22}$ Furthermore, the $\mathrm{Ni}^{\mathrm{IV}}-\mathrm{N}$ distance of $2.02 \AA$ in 3 is substantially shorter than in $\left[(\mathrm{L})_{2} \mathrm{Mn}(\mathrm{IV})_{2}(\mu-\mathrm{O})_{3}\right]^{2+}(2.11 \AA)$. The $\mathrm{Ni}^{\mathrm{IV}}-(\mu-\mathrm{O})$ distance in 3 of $1.85 \AA$ is however similar to that in the $\mathrm{Mn}^{\mathrm{IV}}$ analogue $(1.82 \AA)$. Overall, the DFT structure for 3 and the X-ray structure for $\left[(\mathrm{L})_{2} \mathrm{Mn}(\mathrm{IV})_{2}(\mu-\mathrm{O})_{3}\right]^{2+}$ are similar, which is apparent when superimposed (Figure S34).

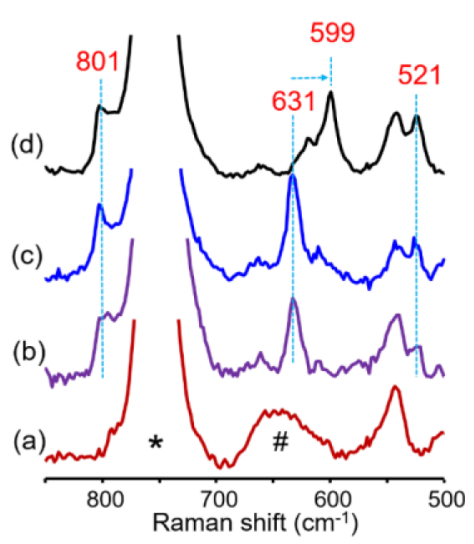

Figure 4. Raman spectra $\left(\lambda_{\text {exc }} 532 \mathrm{~nm}\right)$ of $1(3.5 \mathrm{mM})$ in acetonitrile (a) and with (b) 4.5 equiv of $\mathrm{NaOBr}$, (c) 4.5 equiv of $\mathrm{Na}^{16} \mathrm{OCl}$, and (d) 4.5 equiv of $\mathrm{Na}^{18} \mathrm{OCl}$. *Solvent band. "Raman band from quartz.

The Raman spectrum of 3, with excitation resonant with the visible absorption band, shows enhanced Raman scattering at 801,631 , and $521 \mathrm{~cm}^{-1}$ (Figure 3), with only the band at 631 $\mathrm{cm}^{-1}\left(\Delta\left[{ }^{18} \mathrm{O}\right]=32 \mathrm{~cm}^{-1}\right)$ affected by the use of $\mathrm{Na}^{18} \mathrm{OCl}$. The bands are unaffected by use of $\mathrm{OBr}^{-}$in place of $\mathrm{OCl}^{-}$. The DFT-calculated Raman spectrum for $\left[(\mathrm{L})_{2} \mathrm{Ni}\right.$ $\left.(\mathrm{IV})_{2}\left(\mu-{ }^{16 / 18} \mathrm{O}\right)_{3}\right]^{2+}$ (3) shows a penta-atomic symmetric stretching $\mathrm{Ni}-(\mathrm{O})_{3}-\mathrm{Ni}$ mode at $638 \mathrm{~cm}^{-1}$, which shifted to $609 \mathrm{~cm}^{-1}$ upon isotope labeling (i.e., $\Delta\left[{ }^{18} \mathrm{O}\right]=29 \mathrm{~cm}^{-1}$, Figure S35). Mixed labeling (i.e., varying ratios of ${ }^{16} \mathrm{O}$ and ${ }^{18} \mathrm{O}$ ) experiments show the series of four bands expected for the four isotopologues and correspond well with the DFT-calculated shifts (Figure 5).

The band at $801 \mathrm{~cm}^{-1}$ corresponds to a symmetric $\mathrm{Ni}-\mathrm{N}$ stretching (calcd by DFT at $782 \mathrm{~cm}^{-1}$, at the same position upon ${ }^{18} \mathrm{O}$ labeling), while the band at $521 \mathrm{~cm}^{-1}$ involves mainly a combination of $\mathrm{Ni}-\mathrm{N}$ and $\mathrm{Ni}-\mathrm{O}$ stretching (calcd by DFT at $517 \mathrm{~cm}^{-1}$ and at $516 \mathrm{~cm}^{-1}$ upon ${ }^{18} \mathrm{O}$ labeling). All of the 


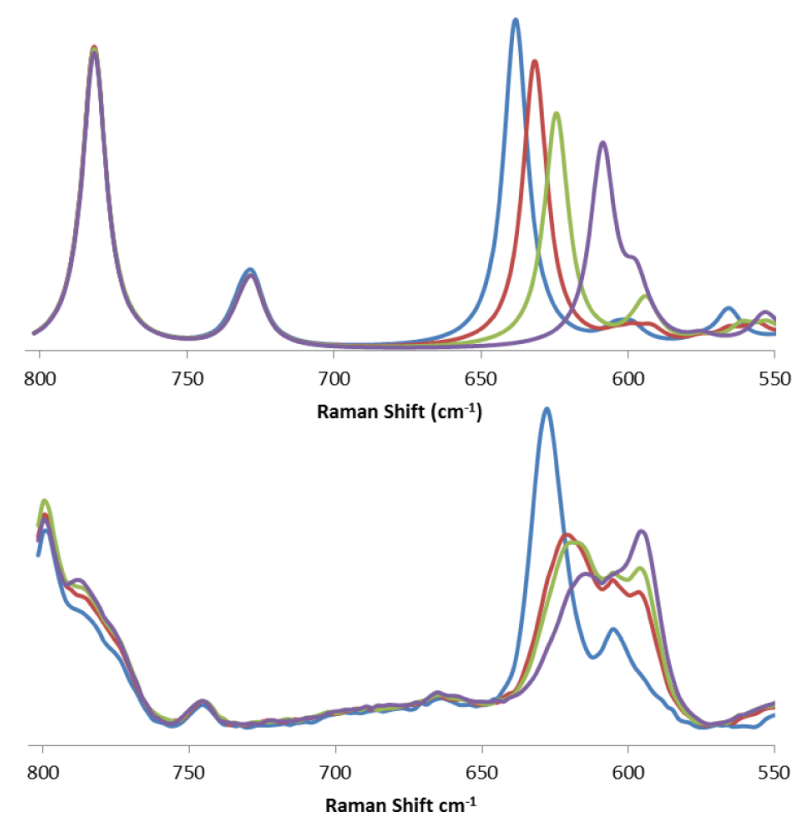

Figure 5. Top: Calculated spectra for 3 with various degrees of ${ }^{18} \mathrm{O}$ substitution $\left({ }^{16} \mathrm{O}_{3}\right.$ (blue), ${ }^{16} \mathrm{O}_{2}{ }^{18} \mathrm{O}$ (red), ${ }^{16} \mathrm{O}^{18} \mathrm{O}_{2}$ (green), ${ }^{18} \mathrm{O}_{3}$ (purple)). Bottom: Resonance Raman spectra of 3 generated from 1 $(4 \mathrm{mM})$ in methanol by addition of 4 equiv of $\mathrm{NaOCl} / \mathrm{H}_{2} \mathrm{O}$ with (blue) $100 \%{ }^{16} \mathrm{O}$, (red) $50 \%{ }^{18} \mathrm{O}$, (green) $34 \%{ }^{18} \mathrm{O}$, and (purple) $26 \%$ ${ }^{18} \mathrm{O}$.

vibrations of the normal modes are available in the SI. The modes observed for 3 are similar in energy to those of the isostructural complex $\left[(\mathrm{L})_{2} \mathrm{Mn}(\mathrm{IV})_{2}(\mu-\mathrm{O})_{3}\right]^{2+}$, which shows a $\mathrm{Mn}-(\mathrm{O})_{3}-\mathrm{Mn}$ stretch at $701 \mathrm{~cm}^{-1}\left(\Delta^{18} \mathrm{O}=33 \mathrm{~cm}^{-1}\right){ }^{23}$ Furthermore, the spectrum is similar to that reported by Riordan and co-workers for $\left[\left(\left(\mathrm{PhTt}^{\mathrm{tBu}}\right) \mathrm{Ni}(\mathrm{III})\right)_{2}(\mu \text {-O })_{2}\right]$, with a band at $585 \mathrm{~cm}^{-1}\left(\Delta\left[{ }^{18} \mathrm{O}\right]=30 \mathrm{~cm}^{-1}\right),{ }^{24}$ and by Fukuzumi and co-workers for $\left[\left(\mathrm{L}^{\prime} \mathrm{Ni}(\mathrm{III})\right)_{2}(\mu-\mathrm{O})_{2}\right]^{2+}$, where $\mathrm{L}^{\prime}=\mathrm{N}, \mathrm{N}$ bis[2-(2-pyridyl)ethyl]-2-phenylethylamine, with a band at 612 $\mathrm{cm}^{-1}\left(\Delta\left[{ }^{18} \mathrm{O}\right]=32 \mathrm{~cm}^{-1}\right) .{ }^{25}$ The higher Raman shift for 3 is consistent with an increase in the oxidation state from III to IV.

The $\mathrm{Ni}-\mathrm{O}-\mathrm{O}-\mathrm{Ni}$ stretching modes in $3 \mathbf{a}$ are expected at higher wavenumbers compared to $\mathrm{Ni}-\mathrm{O}-\mathrm{Ni}$ modes; see, for example, the $\mathrm{O}-\mathrm{O}$ stretch vibrations reported by Riordan and co-workers $\left(\left[(\mathrm{Ni}(\mathrm{tmc}))_{2}(\mu\right.\right.$-O-O $\left.)\right]$ at $778 \mathrm{~cm}^{-1} ; \Delta\left[{ }^{18} \mathrm{O}\right]=43$ $\left.\mathrm{cm}^{-1}\right)^{26}$ and Gade and co-workers $\left([(\mathrm{Ni} \text { (iso-pmbox }))_{2}(\mu\right.$-O$\mathrm{O})]$ at $\left.742 \mathrm{~cm}^{-1} ; \Delta\left[{ }^{18} \mathrm{O}\right]=36 \mathrm{~cm}^{-1}\right) .{ }^{27}$ This conclusion is supported by the DFT-calculated IR spectrum for 3a (Figure $\mathrm{S} 36)$, which shows an $\mathrm{O}-\mathrm{O}$ stretching band $\left(\Delta\left[{ }^{18} \mathrm{O}\right]\right.$ in parentheses) at $892(841) \mathrm{cm}^{-1}$, a Ni-N stretching mode at $768(768) \mathrm{cm}^{-1}$, and $\mathrm{Ni}-\mathrm{O}$ bending/stretching modes at 663 (633), 601 (594), $585(571)$, and $536(516) \mathrm{cm}^{-1}$. Of these modes, the 663 and $768 \mathrm{~cm}^{-1}$ modes are strongly IR active. Therefore, given that in the present system only the band at $631 \mathrm{~cm}^{-1}$ is affected by the use of ${ }^{18} \mathrm{OCl}^{-}$and that the DFTcalculated IR spectrum of 3a (Figure S36) indicates bands at ca. 660 and $770 \mathrm{~cm}^{-1}$ only and not a band at $\mathrm{ca} .801 \mathrm{~cm}^{-1}$, the peroxy species can be discarded. The same is true for $3 \mathbf{b}$, which shows terminal-oxo Ni-O stretches at $742 \mathrm{~cm}^{-1}$ (shifting to $718 \mathrm{~cm}^{-1}$ upon ${ }^{18} \mathrm{O}$ labeling, i.e., $\left.\Delta^{18} \mathrm{O}=24 \mathrm{~cm}^{-1}\right), 700 \mathrm{~cm}^{-1}$ $\left(\Delta^{18} \mathrm{O}=28 \mathrm{~cm}^{-1}\right)$, and $689 \mathrm{~cm}^{-1}\left(\Delta^{18} \mathrm{O}=26 \mathrm{~cm}^{-1}\right)$; the Ni$\left(\mu\right.$-O) $-\mathrm{Ni}$ stretch is found at $653 \mathrm{~cm}^{-1}\left(\Delta^{18} \mathrm{O}=17 \mathrm{~cm}^{-1}\right)$. No bands are observed around $521 \mathrm{~cm}^{-1}$, and all bands show significant isotope effects. Therefore, although the ESI mass spectral data could correspond also to a peroxy-bridged (3a) or the mono- $\mu$-oxo species ( $3 \mathbf{b})$, the most appropriate structural assignment for the high-valent nickel species is 3 based on the vibrational spectra.

DFT calculations provide further support for this assignment in the thermochemistry of the reaction of $\mathbf{1}$ and $\mathbf{2}$ with $\mathrm{NaOCl}$ to form 3. Mass spectral data indicate that the reactive intermediate 3 has the composition $\left[(\mathrm{L})_{2} \mathrm{Ni}_{2} \mathrm{O}_{3}\right]^{2+}$, and the absence of EPR (X-band) signals at $77 \mathrm{~K}$ at any time suggests that mononuclear $\mathrm{Ni}(\mathrm{III})$ complexes are not present to a significant extent. Hence, geometry optimizations were performed with all spin multiplicities for 1, 2, 3, and 3a, as well as possible mononuclear $\mathrm{Ni}(\mathrm{II})$ complexes, e.g., $[(\mathrm{L}) \mathrm{Ni}$ (II) $\left.\left(\mathrm{CH}_{3} \mathrm{CN}\right)_{3}\right]^{2+}(4)$ and $\left[(\mathrm{L}) \mathrm{Ni}(\mathrm{II})\left(\mathrm{CH}_{3} \mathrm{CN}\right)_{2}\right]^{2+}(5)$ (Table $\mathrm{S} 2)$. Antiferromagnetically coupled dinuclear species were found as lowest energy for $\mathbf{1}, \mathbf{2}, \mathbf{3} \mathbf{a}$, and $\mathbf{3 b}$, while a closedshell spin state was found for 3 (vide supra); a high-spin $\mathrm{Ni}$ (II) $(S=1)$ ground state was found for 4 and $\mathbf{5}$. The reactions of 1 with $\mathrm{NaOCl}$ to form 3, 3a, or $\mathbf{3 b}$ (Scheme 3) were calculated to be exergonic by $-92.5,-88.1$, and $-50.3 \mathrm{kcal} \cdot \mathrm{mol}^{-1}$, respectively; hence, 3 is $4.46 \mathrm{kcal} \cdot \mathrm{mol}^{-1}$ more stable than $3 \mathrm{a}$ and $42.2 \mathrm{kcal} \cdot \mathrm{mol}^{-1}$ than $3 \mathbf{b}$, in terms of Gibbs energy (in electronic energy: 7.50 and $46.11 \mathrm{kcal} \cdot \mathrm{mol}^{-1}$, respectively for $3 \mathrm{a}$ and $\mathbf{3 b}$ ), Table $\mathrm{S} 3$.

Further spectroscopic evidence for the formation of 3 , and not $\mathbf{3 a}$ or $\mathbf{3 b}$, is obtained by mixed labeling experiments. In these experiments we applied ratios of pure ${ }^{16} \mathrm{O}(3: 0)$, pure ${ }^{18} \mathrm{O}$ $(0: 3)$, and 1:2/2:1 mixtures of these, such that we would have four different distributions with on average the incorporation of $0,1,2$, and 3 labeled oxygens into the complex. The observed isotope shifts observed in our Raman spectra with these mixed labeling experiments match perfectly with the corresponding DFT isotope shifts; that is, the $631 \mathrm{~cm}^{-1}$ peak $\left(638 \mathrm{~cm}^{-1} \mathrm{DFT}\right)$ shifts to $623 \mathrm{~cm}^{-1}\left(630 \mathrm{~cm}^{-1} \mathrm{DFT}\right)$, to $613 \mathrm{~cm}^{-1}\left(622 \mathrm{~cm}^{-1}\right.$ DFT), and finally to $599\left(609 \mathrm{~cm}^{-1}\right.$ DFT).

Overall, the spectroscopic and computational data are consistent with the assignment of the intermediate as 3 $\left(\left[(\mathrm{L})_{2} \mathrm{Ni}(\mathrm{IV})_{2}\left(\mu{ }^{16} \mathrm{O}\right)_{3}\right]^{2+}\right)$. The mechanism by which 3 forms from $\mathrm{Ni}$ (II) complexes undoubtedly involves multiple elementary steps. However, the coordination of $\mathrm{OCl}^{-}$to $\mathrm{Ni}(\mathrm{II})$ is expected to be facile given the rapid exchange of $\mathrm{Cl}^{-}, \mathrm{Br}^{-}$, and $\mathrm{CH}_{3} \mathrm{CN}$ ligands. Heterolytic cleavage of $\mathrm{Ni}(\mathrm{II})-\mathrm{O}-\mathrm{Cl}$ to form a transient intermediate $\mathrm{Ni}(\mathrm{IV})$ species and $\mathrm{Cl}^{-}$is presumably followed by formation of a $(\mu-\mathrm{O})_{3}$-bridged $\mathrm{Ni}(\mathrm{IV})$ dimer, which does not show antiferromagnetic coupling, in contrast with the equivalent manganese complex, but instead corresponds to diamagnetic closed-shell $\mathrm{Ni}(\mathrm{IV})$ ions.

Finally, although 3 undergoes rapid self-decay in methanol to yield formaldehyde, in acetonitrile it is relatively stable, allowing for its reactivity with organic substrates to be assessed. The addition of ca. 4 equiv of substrate (e.g., xanthene, 9,10dihydroanthracene, and fluorene) resulted in a complete loss of absorbance at $612 \mathrm{~nm}$ within ca. $6 \mathrm{~min}$ (70, 150, and $350 \mathrm{~s}$, respectively, Figure S37). At $-15{ }^{\circ} \mathrm{C}, 3$ is stable for over $6 \mathrm{~h}$ (Figure S38); however, addition of 4 equiv of xanthene resulted in a rapid loss in absorbance at $612 \mathrm{~nm}$ (within ca. 275 $\mathrm{s}$, Figure S39). Addition of 50 equiv of fluorene to 3 resulted in the disappearance of the signal at $m / z 253.3$ and a recovery of the signals of 1 and 4 (Figure S40). Hence, although substrates react directly with $\mathrm{NaOCl}, 3$ engages in $\mathrm{C}-\mathrm{H}$ oxidation also (Figure S39). 


\section{CONCLUSIONS}

Complex 3 represents the first example of a $\mathrm{Ni}(\mathrm{IV})$-oxidobridged dimer. Its generation from $\mathrm{NaOCl}$ and subsequent reaction with organic substrates opens up the possibility to use $\mathrm{NaOCl}$ as a terminal oxidant. The intermediacy of a transition metal catalyst opens the possibility of engaging in selective oxidations, thereby taming the reactivity of this potent oxidant.

\section{ASSOCIATED CONTENT}

\section{S Supporting Information}

The Supporting Information is available free of charge on the ACS Publications website at DOI: 10.1021/jacs.7b04158.

Animated gifs for selected vibrational modes between 517 and $893 \mathrm{~cm}^{-1}$ of 3 (ZIP)

Animated gifs for selected vibrational modes between 536 and $892 \mathrm{~cm}^{-1}$ of $3 a$ (ZIP)

Animated gifs for vibrational modes at 653, 689, 700, 742 $\mathrm{cm}^{-1}$ of $3 \mathbf{b}$ (ZIP)

Details of synthesis and charcaterization of complexes $\mathbf{1}$, 2, and 4, UV-vis absorption, (resonance) Raman, NMR, EPR spectroscopy, ESI-MS, XANES, XES, and computational data (PDF)

\section{AUTHOR INFORMATION}

\section{Corresponding Authors}

*marcel.swart@udg.edu

*w.r.browne@rug.nl

\section{ORCID $\odot$}

David J. Martin: 0000-0002-3549-4202

Marcel Swart: 0000-0002-8174-8488

Wesley R. Browne: 0000-0001-5063-6961

\section{Notes}

The authors declare no competing financial interest.

\section{ACKNOWLEDGMENTS}

The Ubbo Emmius fund of the University of Groningen, the European Research Council (StG, no. 279549, W.R.B.), NWO for a VIDI grant (723.014.010, D.J.M. and M.T.), The Netherlands Ministry of Education, Culture and Science (Gravity program 024.001.035, W.R.B.), MINECO (CTQ2014-59212-P and CTQ2015-70851-ERC, M.S.), GenCat (2014SGR1202, M.S.), FEDER (UNGI10-4E-801, M.S.), and COST action CM1305 "ECOSTBio" (W.R.B., COSTSTSM-CM1305-29045) are acknowledged for financial support. A. van Dam (ERIBA) is thanked for assistance with mass spectrometry.

\section{REFERENCES}

(1) (a) Costas, M.; Mehn, M. P.; Jensen, M. P.; Que, L., Jr. Chem. Rev. 2004, 104, 939-986. (b) Solomon, E. I.; Brunold, T. C.; Davis, M. I.; Kemsley, J. N.; Lee, S.-K.; Lehnert, N.; Neese, F.; Skulan, A. J.; Yang, Y.-S.; Zhou, J. Chem. Rev. 2000, 100, 235-350. (c) Punniyamurthy, T.; Velusamy, S.; Iqbal, J. Chem. Rev. 2005, 105, 2329-2363.

(2) (a) Decker, A.; Solomon, E. I. Curr. Opin. Chem. Biol. 2005, 9, 152-163. (b) Bertini, I.; Gray, H. B.; Stiefel, E. I.; Valentine, J. S. Biological.Inorganic Chemistry. Structure \& Reactivity; University Science Books: Sausalito, CA, 2007. (c) Meunier, B. Chem. Rev. 1992, 92, 1411-1456. (d) Nam, W. Acc. Chem. Res. 2015, 48, 2415-2423. (e) Oloo, W. N.; Que, L. Acc. Chem. Res. 2015, 48, 2612-2621.

(3) Shearer, J. Acc. Chem. Res. 2014, 47, 2332-2341.

(4) (a) Cho, J.; Kang, Y.; Liu, L. V.; Sarangi, R; Solomon, E. I.; Nam, W. Chem. Sci. 2013, 4, 1502-1508. (b) Honda, K.; Cho, J.;
Matsumoto, T.; Roh, J.; Furutachi, H.; Tosha, T.; Kubo, M.; Fujinami, S.; Ogura, T.; Kitagawa, T.; Suzuki, M. Angew. Chem., Int. Ed. 2009, 48, 3304-3307. (c) Tano, T.; Doi, Y.; Inosako, M.; Kunishita, A.; Kubo, M.; Ishimaru, H.; Ogura, T.; Sugimoto, H.; Itoh, S. Bull. Chem. Soc. Jpn. 2010, 83, 530-538. (d) Kunishita, A.; Doi, Y.; Kubo, M.; Ogura, T.; Sugimoto, H.; Itoh, S. Inorg. Chem. 2009, 48, 4997-5004. (e) Morimoto, Y.; Bunno, S.; Fujieda, N.; Sugimoto, H.; Itoh, S. J. Am. Chem. Soc. 2015, 137, 5867-5870.

(5) (a) Corona, T.; Pfaff, F. F.; Acua-Pares, F.; Draksharapu, A.; Whiteoak, C. J.; Martin-Diaconescu, V.; Lloret-Fillol, J.; Browne, W. R; Ray, K.; Company, A. Chem. - Eur. J. 2015, 21, 15029-15038. (b) Pfaff, F. F.; Heims, F.; Kundu, S.; Mebs, S.; Ray, K. Chem. Commun. 2012, 48, 3730-3732.

(6) (a) Draksharapu, A.; Codolá, Z.; Gómez, L.; Lloret-Fillol, J.; Browne, W. R; Costas, M. Inorg. Chem. 2015, 54, 10656-10666. (b) Pirovano, P.; Farquhar, E. R.; Swart, M.; McDonald, A. R. J. Am. Chem. Soc. 2016, 138, 14362-14370. (c) Corona, T.; Draksharapu, A.; Padamati, S. K.; Gamba, I.; Martin-Diaconescu, V.; Acuña-Parés, F.; Browne, W. R.; Company, A. J. Am. Chem. Soc. 2016, 138, 1298712996.

(7) Corona, T.; Company, A. Chem. - Eur. J. 2016, 22, 13422-13429.

(8) (a) Camasso, N. M.; Sanford, M. S. Science 2015, 347, 1-7. (b) Riordan, C. G. Science 2015, 347, 1203.

(9) (a) Gray, H. B.; Hare, C. R. Inorg. Chem. 1962, 1, 363-368. (b) O’Halloran, K. P.; Zhao, C.; Ando, N. S.; Schultz, A. J.; Koetzle, T. F.; Piccoli, P. M. B.; Hedman, B.; Hodgson, K. O.; Bobyr, E.; Kirk, M. L.; Knottenbelt, S.; Depperman, E. C.; Stein, B.; Anderson, T. M.; Cao, R.; Geletii, Y. V.; Hardcastle, K. I.; Musaev, D. G.; Neiwert, W. A.; Fang, X.; Morokuma, K.; Wu, S.; Kögerler, P.; Hill, C. L. Inorg. Chem. 2012, 51, 7025-7031.

(10) Wieghardt, K.; Schmidt, W.; Herrmann, W.; Kueppers, H. J. Inorg. Chem. 1983, 22, 2953-2956.

(11) Bossek, U.; Nühlen, D.; Bill, E.; Glaser, T.; Krebs, C.; Weyhermüller, T.; Wieghardt, K.; Lengen, M.; Trautwein, A. X. Inorg. Chem. 1997, 36, 2834-2843.

(12) (a) Klamt, A.; Schüürmann, G. J. Chem. Soc., Perkin Trans. 2 1993, 799-805. (b) Pye, C. C.; Ziegler, T. Theor. Chem. Acc. 1999, 101, 396-408. (c) Swart, M.; Rösler, E.; Bickelhaupt, F. M. Eur. J. Inorg. Chem. 2007, 2007, 3646-3654.

(13) van Lenthe, E.; Baerends, E. J.; Snijders, J. G. J. Chem. Phys. 1993, 99, 4597-4610.

(14) (a) Swart, M. Chem. Phys. Lett. 2013, 580, 166-171. (b) Becke, A. D. Phys. Rev. A: At., Mol., Opt. Phys. 1988, 38, 3098-3100. (c) Perdew, J. P. Phys. Rev. B: Condens. Matter Mater. Phys. 1986, 33, 8822-8824.

(15) At S12g/TZ2P//BP86-D3/TDZP.

(16) Tak, H.; Lee, H.; Kang, J.; Cho, J. Inorg. Chem. Front. 2016, 3, 157-163.

(17) (a) Sun, Y.-K; Kim, M. G.; Kang, S. H.; Amine, K. J. Mater. Chem. 2003, 13, 319-322. (b) Gu, W.; Wang, H.; Wang, K. Dalton Trans. 2014, 43, 6406-6413.

(18) Rehr, J. J.; Kas, J. J.; Vila, F. D.; Prange, M. P.; Jorissen, K. Phys. Chem. Chem. Phys. 2010, 12, 5503-5513.

(19) In the absence of $\mathrm{Ni}(\mathrm{II})$ or $\mathbf{1}, \mathrm{NaOCl}$ is stable in $\mathrm{CH}_{3} \mathrm{CN}$.

(20) This complex is reminiscent of the $\left(\mu-\eta_{2}: \eta_{2}\right.$-disulfido) dinickel(II) complexes with 6-methyl-TPA ligands reported by Itoh et al.; see: Inosako, M.; Kunishita, A.; Kubo, M.; Ogura, T.; Sugimoto, T.; Itoh, S. Dalton Trans. 2009, 43, 9410-9147.

(21) The formation of species such as $(\mathrm{O}=\mathrm{Ni}(\mathrm{IV})-\mathrm{O}-\mathrm{Ni}(\mathrm{IV})=\mathrm{O})$ is highly unlikely, as it is calculated to lie 45 to $58 \mathrm{kcal} \mathrm{mol}^{-1}$ (depending on functional used, e.g., BP86-D3 and S12g) higher in energy than even the peroxy species 3a. Furthermore, DFT calculations indicate a high tendency for a species to converge to the structure of the 3a species. In addition ligand hydroxylation can be discounted on the basis of the recovery of the $\mathrm{Ni}$ (II) complexes, e.g., 1 and $\mathbf{4}$, once 3 has reacted with solvent or substrate.

(22) Wieghardt, K.; Bossek, U.; Nuber, B.; Weiss, J.; Bonvoisin, J.; Corbella, M.; Vitols, S. E.; Girerd, J. J. J. Am. Chem. Soc. 1988, 110, 7398-7411. 
(23) (a) Hage, R.; Krijnen, B.; Warnaar, J. B.; Hartl, F.; Stufkens, D. J.; Snoeck, T. L. Inorg. Chem. 1995, 34, 4973-4978. (b) Angelone, D.; Abdolahzadeh, S.; de Boer, J. W.; Browne, W. R. Eur. J. Inorg. Chem. 2015, 21, 3532-3542.

(24) Mandimutsira, B. S.; Yamarik, J. L.; Brunold, T. C.; Gu, W.; Cramer, S. P.; Riordan, C. G. J. Am. Chem. Soc. 2001, 123, 9194-9195. $\mathrm{PhTttBu}=$ phenyltris $(($ tert-butylthio $)$ methyl $)$ borate.

(25) Itoh, S.; Bandoh, H.; Nakagawa, M.; Nagatomo, S.; Kitagawa, T.; Karlin, K. D.; Fukuzumi, S. J. Am. Chem. Soc. 2001, 123, 1116811178.

(26) Kieber-Emmons, M. T.; Schenker, R; Yap, G. P. A.; Brunold, T. C.; Riordan, C. G. Angew. Chem. 2004, 116, 6884-6886. tmc $=$ 1,4,8,11-tetramethyl-1,4,8,11-tetraazadodecane.

(27) Rettenmeier, C. A.; Wadepohl, H.; Gade, L. H. Angew. Chem., Int. Ed. 2015, 54, 4880-4884. iso-pmbox = bis(oxazolinylmethylidene)pyrrolidine. 